\title{
Papers
}

\section{The phoenix rises from the ashes: Advertising and content monetization in a digital world}

\author{
Subhankar Bhattacharya \\ is Principal Solutions Consultant in the Infosys Technologies Media and Entertainment Practice. He is one of the key leads within \\ the Infosys Digital Media Enterprise solution architecture team. Along with experience in Media \& Entertainment, he brings with \\ him extensive cross industry experience in Retail, Hospitality and Manufacturing, in areas such as Supply Chain Management, \\ CRM and Pricing Management in building innovative solutions for the Media industry.
}

\section{Edward Scott}

is Principal, Media \& Entertainment, Infosys Technologies. As a Principal in the M\&E practice, he is one of the lead architects developing IT-enabled business solutions for Infosys' M\&E clients. He is also a key driver of the company's Digital Media Enterprise framework and its Media Operations Outsourcing initiative. He is charged with developing integrated and adaptable approaches to optimizing the creation, distribution, consumption and monetization of digital content.

\section{Magan Arthur}

is Senior Principal Solutions Consultant in the Infosys Technologies Media and Entertainment Practice. He has more than 15 years of experience helping companies plan and deploy digital media technology strategies. As a senior principal in the M\&E practice, he is leading the digital media group and spearheads the Digital Media Enterprise initiative at Infosys. He is the author of Expanding a Digital Content Management System for the Growing Digital Media Enterprise published in 2006 by Focal Press.

Keywords: media, peer-to-peer, advertising, DVR, VOD, tivo

Abstract Rapid adoption of new technologies in the Media world is accelerating the evolution of entertainment from its long history of catering to the masses towards business models that incorporate more personal, relevant and reciprocal media experiences for consumers. Driving these changes are unprecedented advances in the production, distribution and consumption of content. The net outcome of all this tumult will be nothing short of revolutionary. Media content (and all its affiliated data) will originate in digital form and will exist as such throughout its usable lifecycle. It will be easily retrieved and managed. And it will be transferred around the globe on demand, instantaneously and in seamless form. For key stakeholders in the media creation value chain, the intervening period will be characterized by experimentation and profit gains - as well as challenges and corporate failures. Navigating these waters will require a new blend of business, technical and creative skills. Success will necessitate comfort with technology, openness to change, aggressiveness with resource commitments and willingness to take some calculated risks. Given the uncertain environment at this stage, the chorus of concerned corporate citizens is understandable. Yet from this chaos will emerge a new Media construct. As the dust settles, entertainment - now in digital form - will experience a boon on a scale never witnessed before in Media history. Part One of this series explores the drivers, opportunities, variables and implications of the changing Media \& Entertainment

Magan Arthur Email: magan@ arthurconsultinggroup. com landscape on content providers, advertisers and the consumer. Part Two of the series lays out a high-level roadmap for Media \& Entertainment companies architecting this future.

Journal of Digital Asset Management (2006) 2, 269-278. doi:10.1057/palgrave.dam.3650046 


\section{DRIVERS OF CHANGE}

\section{Modern media: A view through the looking-glass}

By definition, entertainment is meant to entertain. At its core lies the consumer. As the universe of content choice and flexibility opens up to consumers, they will begin to fall in to one of three profiles. Some will be active consumers or content "seekers." Others will rely on "taste makers" to choose content for them. Still others will remain "passive viewers," letting the market determine their content preferences.

Each of these segments has profound implications on the processes and approach by which content will be produced and distributed. As they develop their long-term plans, content providers will need to prepare for this hybrid environments of media consumers. The one-size-fits-all approach is a thing of the past. Technology is shifting the foundation of the Media \& Entertainment industry, with advantage moving from creator to consumer.

Behind this modern content revolution is a dynamic group of innovators - companies and individuals whose cumulative efforts have chipped away at established content distribution and consumption models. Their inventions have exposed the opportunities that lay ahead and hinted at the uncertain business environment that has followed. The unintended (and sometimes intended) consequence has been an environment characterized by a loss of control over intellectual property in the short term and a complete disruption of content business models in the longer term.

Some of these key innovations are listed below:

\begin{tabular}{|c|c|}
\hline Factor & Impact \\
\hline Peer-to-Peer Networks & $\begin{array}{l}\text { The meteoric rise and subsequent fall of Napster encapsulates both the wants and } \\
\text { needs of the new consumer content market. P2P networks proved that consumers are } \\
\text { eager to exchange and share information. They also showed that in an unprotected } \\
\text { digital environment, however, this eagerness can quickly translate into a free-for-all of } \\
\text { illegal content sharing. While the luster of P2P networks has dimmed, look for the } \\
\text { technology to evolve and play an important role in legal content sharing. }\end{array}$ \\
\hline iTunes \& the iPod & $\begin{array}{l}\text { The massive success of Apple in creating a complete distribution-to- } \\
\text { consumption content downloading ecosystem proved that, given a simple, } \\
\text { secure and fairly priced environment, consumers will acquire and consume } \\
\text { digital media legally. The challenge for Apple is that consumers are becoming less } \\
\text { tolerant of controlled content environments. Look to Apple to begin licensing their } \\
\text { technology, allowing interoperability with other devices/applications. }\end{array}$ \\
\hline $\begin{array}{l}\text { Digital Video } \\
\text { Recorders }\end{array}$ & $\begin{array}{l}\text { Popularized by TiVo, DVRs introduced into our cultural lexicon the concept of " } \\
\text { time-shifting," where consumers are no longer tethered to the dictates of a } \\
\text { broadcaster's programming schedule. DVRs gave "intelligence" to VCRs by tying } \\
\text { them to the database of programming schedules. Consumers can now watch } \\
\text { broadcast programming whenever they want. Pretty soon, the notion of "prime } \\
\text { time" and "appointment television" will disappear. The success of DVRs enabled the } \\
\text { technology to migrate to Service Provider set-top boxes. Of concern to advertisers, } \\
\text { however, the technology also makes it easier for consumers to skip commercials. }\end{array}$ \\
\hline Sling Media & $\begin{array}{l}\text { By connecting DVRs to the internet, Sling Media takes the content-shifting } \\
\text { environment to the new dimension of "location-shifting." The technology } \\
\text { allows content stored on a DVR-type device to be accessed by any broadband- } \\
\text { connected PC anywhere in the world. Because of its point-to-point nature, the } \\
\text { technology has managed to avoid the rights management issues faced by other } \\
\text { content sharing technologies - at least for the time being. Like the DVRs, look } \\
\text { to Sling Media's technology to become commoditized and migrate onto set-top } \\
\text { boxes. }\end{array}$ \\
\hline $\begin{array}{l}\text { Play } \\
\text { Station Portable }\end{array}$ & $\begin{array}{l}\text { Much as with its Walkman product, Sony's PSP represents a simple consumer } \\
\text { device with powerful capabilities. Its high-resolution screen and robust computing } \\
\text { power has made PSP the mobile gaming device of choice among consumers. } \\
\text { PSP's success also highlights another trait of the new media environment: } \\
\text { consumers want mobility with their content. }\end{array}$ \\
\hline
\end{tabular}


Online DVD Rentals

Video-on-Demand

Computing and

Compression

Technologies

Memory and Storage Technologies

Fiber-to-theneighborhood and Fiber-to- the-home

Blue Tooth and WiMax Deployment

Collapse of Content Window

Emergence of IPTV
Look to PSP and its imitators to become central players in the trend towards seamless consumption of content across delivery platforms. They could even integrate (and co-opt) the role of other mobility devices, such as mobile phones, Blackberries and Palm Pilots.

With its DVD-by-mail business model and "keep it as long as you want" approach, Netflix took on retail powerhouse Blockbuster and changed the rules of the DVD rental business. Netflix proved that given a facilitated online ordering process, consumers will forgo the instant gratification of getting DVDs in-store (along with their associated late fees) in favor of automated and direct-to-the-home delivery of DVDs based on a self-selected list of preferences and a user-generated recommendation engine. The entire business model of Netflix itself will soon be challenged once full Video-onDemand libraries come online.

As right management and content provisioning issues get resolved, the notion of movies on demand is fast becoming a reality. VOD is the "holy grail" of the new media environment - anytime, anywhere content availability. Yet for VOD, it is the business issues, not technical ones, which create challenges.

Critical among these is how per-download and subscription revenues will be distributed among content creators, distributors and other intermediaries. Nonetheless, the volume, demand and opportunities facilitated by VOD will force these issues to be resolved expediently.

As chip speeds double every 18 months and compression algorithms continually improve the efficiency of transmission, media devices are getting smaller, more powerful and more intelligent. This has lent ever-increasing functionality to networks of connected devices in the home and on the go. Increasingly, these powerful devices are becoming extension of our lifestyles rather than tools to support them.

Memory advancement drives innovation. With capabilities doubling every 12 months, memory

technology is enabling more and more functionality typically resident in intelligent networks to migrate onto

personalized devices. Combined with the advancement of storage technologies in growing the capacity and efficiency of content storage, consumers will soon be given a large degree of control over greater and greater quantities of personalized content.

In their race to compete with Cable and Satellite Providers, Telcos are making enormous investments in capacity by laying fiber closer to consumer homes. For consumers, the net result of all these investments in years to come is assurance that no matter how much media and information is transacted at their home or business, the networks supporting delivery will never reach capacity.

The drive towards standardization around wireless technologies such as BlueTooth and WiMax is enabling a wide variety of devices to communicate and exchange data with seamless ease. In short order, we will have internet and content access to our home networks from anywhere within a metro region. Few will miss the tangle of wires that has dominated our homes for years.

Driven by the increasing availability of media on demand, the concept of content windows - a key driver of revenues in the media business - is gradually disappearing. Increasingly, "day-and-date" release of media on multiple platforms is becoming the norm. Already, movies are being released for download online on the same day as DVDs are released in retail channels. This is forcing the media industry to re-evaluate every process along the media supply chain, from production to planning and marketing to distribution. Inevitably, multi-platform releases of content will become the industry norm.

As the provider business moves into IP networks, a host of new IP-enabled functionality will emerge on our TV screens. We will be able to surf the internet, communicate with our friends and watch a variety of programming - all at the same time and on the same screen. The TV monitor will soon represent "real estate" for content streams, all of which could theoretically be monetized. 
Digital Cinema and Blogs

Google vsYahoo!
The cinema experience as we know it is about to change. With the emergence of Digital Cinema - direct transmission of films to the theater via satellite - the theater screen will have the flexibility of programming that TV Networks have today. Digital transmission reduces the cost of movies from $\$ 2,000 /$ print to virtually nothing. The result will be a wide variety of theater-exhibited product and "event-driven" theatrical screenings. Imagine your Superbowl party at a theater near you.

Arguably, entertainment is a shared experience, primal in nature and with its origins in storytelling. Even as personalization drives the new media environment, consumers will still rely on a network of friends and like-minded individuals to help choose content for them and define their "tastes." Online Social Networks and Blogs are fast becoming critical launch pads of content for niche communities of consumers. Look for areas such as journalism and marketing to be unalterably changed by this phenomenon.

In a universe with thousands of media choices, the biggest threat to content producers and traditional media channels are the companies that help consumers sift through the morass of content. Companies like Google and Yahoo! are using their reigning market position and brand value to drive new monetization opportunities around content aggregation and personalization. Look to these networks to become one-stop shops for media discovery and ad inventory sales.

\section{The content market: Barbarians at the gate}

For decades, the entertainment industry has provided access to its content via a defined set of distribution platforms. The process of "gating" or limiting content within certain distribution "windows" allowed the industry to thrive by deriving profit from the additive total of discreet and consecutive revenue streams. Now the gates are being torn down.

The future of entertainment is not about preventing access to content but rather enabling it. The reality is that consumers will soon be offered the capability to easily search, personalize, filter, retrieve and store any piece of content they desire. New forms of content will emerge - a good share of it generated by consumers themselves - as will new services and "packages" of content. The only issue still unresolved is how this content will be monetized and who will share in the proceeds.

Even as content providers continue to evolve ways of protecting their assets in the near term, their business models are shifting to capitalize on these opportunities. The value proposition for monetizing content in the new Media environment is simply too compelling - and the risks too great that new players will seize profits.

Over time, consumers will be given more control of their content, as well as the ability to share, self-distribute and create social networks around it. They will also be given more choice of content, beyond anything they experience today. They will also be provided with more vehicles through which to search and buy content. Finally, they will enjoy seamless ease in transference of this content across home, office and mobile devices.

As increasing amounts of the world's global content becomes available "on demand," the global content market will grow exponentially. American entertainment and gaming products will soon be available in every corner of the world. Successful Bollywood blockbusters will soon show at a multiplicity of screens near you - along with interviews, behind-the-scenes shorts, games and a full library of movie-related content.

What we are seeing today is only the tip of the iceberg. Before any of this can happen, however, new models for financing and creating content will have to emerge. At issue here is the ability of global producers to create product that can be scaled, marketed and sold on a global level. The demand is there. The pipes are there. Now we just need the content.

\section{The advertising market: A dinosaur in transition}

Since the early days of television, advertising and content have been inextricably linked. The ability of marketers to reach large audiences through this "mass medium" created a cozy 
relationship that has evolved from mid-show "advertiser endorsements" to sophisticated ad campaigns, block ad inventory sales and the standard 30-sec commercial spot.

By shifting and manipulating their programming schedules, Broadcasters created an environment of "appointment television" where large audiences could be drawn to hit shows, and hit shows could then be used as "lead-ins" to drive new or struggling series. These large audiences were then sold at a premium to advertisers, even as their measurement was determined by an imprecise system of home viewer "sampling" pioneered by Nielsen. While consumers had to put up with commercial interruptions, the trade-off is that all this content was free.

Advertisers came to accept inefficiency as the cost of doing business in the media world. They knew that half their advertising dollars were working. They just did not know which half. While marketers had other options for advertising — such as print and outdoor advertising or even advertising in movie theaters - none was more effective than television. Or so they thought.

Meantime, Broadcasters soon settled on a model of content production subsidized by advertising. As television series became more expensive to create and maintain, Broadcasters began "deficit financing" their series, creating large pockets of allocated debt that could only be recouped after a show's lengthy run. The off-network "syndication market" created large per-episode re-run fees for networks and allowed independent and network-affiliated local stations around the country to acquire branded, second-run content as programming for their schedules.

With the emergence of cable networks, advertisers soon realized that more targeted audiences could be reached - at a lower cost - through these channels. The movement of ad dollars from Broadcasting to Cable began. The shift was gradual, yet painful for the Broadcasters. Even as production costs escalated, revenues were being retired from the system. In the late 1990s, Broadcasters were forced to seek new ways of amortizing their content and content revenues across platforms, in many cases through the launch or acquisition of cable networks. Yet they never could have foreseen the havoc that technology would soon wreak on the ad model.

Digital Video Recorder (DVR) technology has provided a facilitated way for consumers to skip through commercials. VOD technology has created a framework for generating television content revenues without advertising. The internet has created new ways of targeting consumers and tailoring messages to fit their profiles. It has also created new ways for advertisers to measure audience response and interact with consumers. In the process, it has thrown a spotlight on the elephant in the room - that the census-method of audience measurement in and of itself is largely ineffective.

As advertisers discovered a new jungle of marketing opportunities, it has become clear that an upgrade of their skill sets will be required. Certain venues or platforms will be better for brand-building, others for product sales. New forms of ad content will be needed for these various platforms. And, with all the data now available, new ways of interpreting that data will be critical. To be sure, the entire system need not be scrapped in its entirety. "Event" programming - such as the Superbowl, the Olympics and even American Idol - is still a great vehicle for the wide dissemination of a marketer's message. But the promise of new platforms and new technology will eventually change the ad model irrevocably.

Already, online advertising has gone through an early evolution. From the early days of intrusive banner and pop-ups ads, online advertising is finally moving towards searchbased ads and streaming ads that accompany online content. The power of search-based advertising is the relevancy of its content. And studies have shown that the more relevant an ad is to the consumer's life, the less likely that they will skip it or react negatively.

Targeted and personalized online advertising - along with content pausing, such as on a DVR - allows advertisers to engage consumers and draw them into new channels of extended ad content. Herein, marketers can introduce deeper messages or more complex product descriptions for consumers.

As the ad industry matures, more and more technology-enhanced (or even technologydriven) advertising models will emerge. Advertisers will uncover ways to limit customer 
dissatisfaction and generate more effective returns on their marketing investments. The most profound impact, however, will be a de-coupling of the traditionally tight relationship between advertisers and content producers.

Like amicable business partners that go their separate ways, they will still work on deals together but both will be looking for a change of pace.

\section{The future of change: Shifting into overdrive}

Aided by cheaper storage costs, faster computing capabilities and advanced software/hardware infrastructure, digitized content has come of age in the 21st century. The result is a complete re-assessment of both the definition and the lifecycle of media content. And, whereas the structure of separate content "windows" has driven Studio \& Network revenues for decades, the concept of single, infinite, on-demand "longtail" windows is now just on the horizon. The very concept of Film and Television as mediums is losing its defining lines.

In the near term, the speed with which the $M \& E$ industry is changing has led to an experimental and somewhat random collection of business models. For scale-dependent content (such as Studio movies and Network Television shows), these will converge into "standards" of content distribution and content pricing. Otherwise, consumer confusion and lost revenues will prevail. The alternative - an auction system for content - is not likely to gain traction as Studios and Networks seek bestattempt predictability in their revenues.

The same cannot be said of user-generated content, which is another area of significant opportunity in the new media world. Increasingly, we will see Studios and Networks integrate professionally produced content with that of consumers, as evidenced by News Corporation's $\$ 580 \mathrm{~m}$ purchase of MySpace.com, a popular social-networking site. The mechanisms for creating, packaging and exhibiting this type of coupled media are just now being developed.

We will also begin to see consumers selfdistribute their own content and attach advertising against it. Already, these options exist, including the tools, framework and vehicles required for consumers to distribute - and monetize - their own digital media. Soon, folks will be able to shoot (or convert) a project digitally, upload it to a popular website, determine the pricing mechanism and wait for the money to roll in (or not). These pricing mechanisms include setting a price for the content and/or allowing the website to attach advertising to the content.

While digitization is transforming the nature of entertainment content, its passage through the supply chain is powered by the explosive growth of broadband internet across the globe. Massive investments in broadband networks witnessed during the dotcom boom - some of which contributed to the failures of companies like Enron and Global Crossing has suddenly become relevant in today's Media world.

These two drivers - digitization of content and broadband growth - supported by transformational technologies in consumption, storage and manipulation of content, are converging to make more content available on more devices, in more ways, via richer experiences. As the market evolves, we will see a continued breakdown of the traditional content production and supply chain, creating new opportunities for both emerging and established players.

In the end, what we are witnessing is the emergence of a new business model where the intrinsic value of content producer and content distributor is yet to be established. Both will have direct connections with the consumer. Both will have to balance consumer choice against intellectual property rights protection. The game is no longer about "eyeballs" or even content, but rather it is about consumer engagement. Both content producers and distributors will tussle over the most valuable currency of this new environment - a consumer's time and attention.

So fasten your seatbelts because things are about to get a little crazy. We are simply in a period of transition. Despite the chaos, the growth of the global media market appears to be secure. As with any market upheaval, there will be winners and there will be losers. Davids will emerge and Goliaths will be toppled. For some of the key players in the media value chain - the content providers, advertisers and consumers - the future has, however, never looked brighter. 


\section{MARKET OPPORTUNITIES}

\section{Content providers - "Some things never change!"}

The entertainment industry is unlike any industry in the world. Oscar-winning screenwriter William Goldman once famously said of the creative business, "nobody knows anything." Seasoned Film or Television executives will tell you that theirs is a failuredriven business. Nobody can predict success but everyone can expect failure.

The entertainment industry is also a hit-driven business and is run by risk-takers. Its economics favor guesswork, gambling and a healthy dose of luck. The success of one Film or Television "mega-hit" often subsidizes a host of breakeven projects and out-and-out losers. Risk is mitigated by packaging product into content "slates" and optimizing assets across all possible platforms.

While some of the processes for creating content may not change in the new Media environment, the economics certainly will. As audiences become more fragmented and in control of their content consumption, content providers will need to capitalize on new platforms - such as distribution of content via broadband and mobile devices - in order to augment lost revenues, generate the financing required for continued content production and fuel corporate growth.

Where technology will play a critical role for content providers is in expanding the reach and penetration of content among consumers. Technology will also enable Studios \& Networks to focus more and more on the business of creating content, rather than the ancillary areas that support the creative process. Content providers can expect a number of new benefits driven by technology:

\begin{tabular}{ll}
\hline Area & Content Provider Opportunities \\
\hline Content & Supplemental revenues derived \\
& from new distribution platforms \\
& and product packaging/pricing \\
& Global consumption of content \\
& will increase, driven by facilitation \\
& of access to global content \\
& Continuing generation of hit \\
& shows will drive new licensing/ \\
& revenue/ad fees in digital space
\end{tabular}

New platforms in digital space will drive new audiences to shows in traditional space New forms of content will emerge, driven by new platforms and new content packages

Greater emphasis on content optimization across platforms should lead to better content Business intelligence systems will enable consumer feedback and input into creative process Streamlining/outsourcing of non-core business and some production processes to enable greater focus on and allocation of assets to content production

Advertising

Global ad market will increase and targeted advertising will enable new marketers to participate

New platforms will not further reduce audiences; they will create larger pools of targeted audiences

New technology will enable better access to (and sales of) cross-platform ad inventory Brand value of content will be extended into digital space and new platforms

The good news for content providers is that some things never change. Despite technological advances in the business, there are limitations on how much of the creative process can be automated.

The filmed entertainment business will always rely heavily on networks of interpersonal relationships and individual judgment. The specialized skills required to develop and create content will ensure that Studios \& Networks play a pre-eminent role in the content market for years to come. After all, someone has to take the Actors, Directors and Talent Agents to dinner.

\section{Advertisers - "Show me the metrics!"}

Since the earliest days of television, broadcasting and advertising have been joined at the hip. As audiences have moved away from the television networks towards content in other platforms, marketers have started to follow. 
Increasingly, the ad world is delivering their messages across both new and "old-school" media channels. This blend of media now includes the internet, broadband content channels, feature film and video game product placement, video game advertising, theatrical pre-film commercials, print, outdoor advertising and (in the near future) mobile media.

Given the clutter, it is getting harder and harder for a marketer to get their message across. In the new Media environment, advertisers will need to be more strategic about how their advertising dollars will be spent. In an environment of personalized content, they will need to develop more specific content, depending on the audience and/or ad platform. Marketers will need to aggressively build out multiple platforms - all at the same time.

As this balancing act evolves, investment will be required from all sides - marketers, ad agencies, content providers and platform providers. New ad content will appear. Systems will emerge to manage multiple products across multiple platforms as well as cross-platform ad campaigns. New skills will be developed. More efficient workflows will surface. Social networks, shared product opinions and word-of-mouth marketing will play increasingly important roles.

For advertisers, these investments will net much better returns on their marketing dollars. For content providers, investment will generate new ad revenues. The key determinants driving investment are the emergence of new metrics to measure audience reach and the ability to interact directly with consumers. It is for this reason that News Corp paid close to $\$ 600 \mathrm{~m}$ to acquire Intermix Media and its social networking site MySpace.com. The site's 66 million members represent a controlled community of content consumers that can be monetized aggressively via advertising and content sales.

As marketers begin to take their message directly to consumers, they will be forced to make sense of their audience's direct response, both quantitative and qualitative. Multiple sources of data will drive marketer decisions, as reach, relevance, frequency, engagement and content effectiveness will all be measured against product qualities and ad campaign objectives.

By the same token, content providers will be forced to deliver proven results to marketers, supported by data that justified the value in their content platform. While one-off or "spot" advertising will open up to a whole new range of smaller marketers, larger ad inventories will likely be sold piecemeal "upfront", as they are in the current television market. This provides marketers (and their intermediaries) with some predictability of market coverage in their ad campaigns.

Technology is enabling more direct measurement of content consumption - and, by association, advertising "consumption" including when, where and how content/ advertising is viewed. The remaining challenge is how to transition the industry from its "standards" - the 30-sec spot and Nielsen ratings - to more dynamic and measurable outcomes systems.

Increasingly, there will also be a disentanglement of advertising and content. Content services that engage consumers will themselves be monetized. One needs only to witness Google's unmatched ad-driven search profitability to understand the direction this market will take.

Thus, for advertisers, new technologies represent a more efficient way of doing business:

\begin{tabular}{ll}
\hline Area & Advertiser Opportunities \\
\hline Content & $\begin{array}{l}\text { Advertising will be more targeted, } \\
\text { down to specific users or niche } \\
\text { audiences } \\
\text { Advertising will be more relevant and } \\
\text { interesting to consumers } \\
\text { Advertising will present more } \\
\text { in-depth information } \\
\text { New platforms would not be } \\
\text { bound by constraints of traditional } \\
\text { advertising (eg 30-sec spot) } \\
\text { Streamlining/outsourcing of non-core } \\
\text { business and some ad production } \\
\text { processes } \\
\text { Feedback } \\
\text { Newstems will enable targeted, } \\
\text { more cost-effective ad campaigns } \\
\text { New platforms will enable richer and } \\
\text { more interactive consumer interactions } \\
\text { Better business intelligence systems } \\
\text { will enable more targeted and } \\
\text { effective advertising } \\
\text { As a result of more relevant ads, } \\
\text { consumer negativity around } \\
\text { advertising should diminish }\end{array}$ \\
\end{tabular}


Metrics

New measurement systems will enable greater control and $\mathrm{ROI}$ on marketing dollars

Greater direct and measurable returns on marketing investment Targeted advertising allows greater customer awareness without proportional rise in costs Measurable determinants can be used to target and personalize ads (eg language, geography)

For years, marketers have relied on imprecise measurements of audience reach/response to gauge the success of their campaigns. Those days will soon be over. We can hear the cheers on Madison Avenue. That is, until reality sets in. There is a lot of the work that lies ahead.

\section{Consumers - "I want my IPTV!"}

Of course, the greatest beneficiaries of the content revolution will be consumers. For years, consumers relied on content producers (and their complicated distribution relationships) in order to access content. Technology — in the form of digital content and digital transmission - has suddenly enabled consumers to be more targeted and selective with their content choices.

Technology has also enabled consumers to be more communal and open with how they store and disseminate content. Rightly or wrongly, the first wave of piracy and illegal distribution in the music industry became a launchpad of learning for content providers. The filmed entertainment market has taken these lessons to heart. The new modus operandi is about creating bridges, not walls.

Rather than worry about a subset of individuals who will always poach content illegally, the business is focusing on enabling consumption for the vast majority of audiences that simply seek ease of access and choice. It is not to say that protecting intellectual property is not a key driver of growth for the business - especially in international markets, where the rule of US law carries less weight. Instead, the approach to rights protection and right management will evolve in tandem with the business models they are intended to support (eg content sales).

By the same token, consumers themselves are changing the very definition of content. Usergenerated and user-distributed content (ie video, photos, blogs, etc) will soon represent a measurable portion of consumed Media. Userdriven local content (ie community events, local sporting events, etc) will gain in importance as well. It is no surprise that popular social networking and blogging websites have become acquisition targets for Studios \& Networks. After all, they represent the ideal new content platform: distribution channel, ad vehicle and user-generated material, all rolled into one.

In the consumer market, content is intimately tied to devices. The desire for mobility is driving the sales of iPods and Sony PSPs. The desire for storage and flexibility is driving the sales of Microsoft XBox and DVRs. The desire for seamless integration of content across devices is driving the adoption of BlueTooth and WiMax standards. And this is just the beginning.

Soon, web-connected televisions, supported by appropriate infrastructure, will deliver multiple streams of side-by-side content to the screen. Television screens will represent content "real estate," with each stream holding the potential to be monetized. How this environment evolves will ultimately depend on the give-and-take between consumers, advertisers and content providers. After all, consumers are already using DVRs to skip commercials. They seek relevance to their lives and less intrusion, not more.

\begin{tabular}{ll}
\hline Area & Consumer Opportunities \\
\hline Control & $\begin{array}{l}\text { Personalization of content (what, } \\
\text { when, how, where) } \\
\text { Greater choice of content (on } \\
\text { global scale) } \\
\text { Ability to create, share and } \\
\text { market self-generated content } \\
\text { Ability to create self-generated } \\
\text { niche audiences for content } \\
\text { Ability to choose between } \\
\text { interactive and passive viewing } \\
\text { experiences } \\
\text { Partnering } \\
\text { Ability to partner with } \\
\text { marketers/content providers } \\
\text { Ability to interact/give feedback } \\
\text { to marketers/content providers } \\
\text { Seamless content experience } \\
\text { across devices and platforms } \\
\text { Occasion to add more and } \\
\text { diverse media content \& forms } \\
\text { of content to their day }\end{array}$ \\
\hline
\end{tabular}


Although it is an over-used adage, Content will truly always be King. The drive to consume content is primordial, tracing its origins to the early days of storytelling. In the modern world, the market for Media \& Entertainment content has never diminished decade-on-decade. And virtually every technological innovation in the industry has been met with first with corporate resistance, then gradual (and sometimes rapid) consumer adoption, followed by sizable growth in the market.

Ultimately, filmed entertainment is a shared experience at some level. The difference these days is that consumers now have the option to personalize their experience down to the communal or individual level. Just like to good old days of Primitive Man and storytelling back in the cave. 